Brandeis $\mid$ urear

brandeis.edu/j-caste
CASTE: A Global Journal on Social Exclusion

Vol. 1, No. 2, pp. 193-2I4

October 2020

ISSN 2639-4928

DOI: $10.26812 /$ caste.v1i2.143

\title{
Assessing the Impact of Public-Private Funded Midday Meal Programs on the Educational Attainment and Well-being of School Children in Uttar Pradesh, India
}

\author{
Joseph K.Assan', Laurence Simon², Dinar D. Kharisma ${ }^{3}$, \\ Afia A.Adaboh ${ }^{4}$, Nicola Assan ${ }^{5}$ and Abdullah Al Mamun ${ }^{6}$
}

\begin{abstract}
The provision of free midday meals at schools is considered to have the potential to enhance human dignity and facilitate equitable access to students from low socio-economic backgrounds, low social status (including caste), and poor households. The paper examines the impact of an internationally funded Indian foundation's Midday Meal (MDM) school feeding program on educational access, performance, participation, and well-being of the beneficiaries. Our study has sampled students and teachers from predominantly Dalit, lower caste, ethnic, and religious minority households within state-run schools in Uttar Pradesh, India's most populous state with the largest number of poor people, as its unit of analysis. The study sought to evaluate the implementation of the MDM program in Lucknow, the state capital, to ascertain whether the strategic program implementation protocols also ensure social inclusion and address various forms of discrimination commonly reported in the literature. The study revealed that students were satisfied with most of the indicators on implementation of the program, serving, and food satisfaction. Nevertheless, we argue that the implementation process could benefit from a more integrated interagency coordination to address concerns regarding at-risk Dalit, lower caste

\footnotetext{
${ }^{1-4}$ Center for Global Development and Sustainability, Heller School for Social Policy and Management, Brandeis University, Waltham, MA, USA

${ }^{5}$ Salford Business School, University of Salford, Salford, Greater Manchester, United Kingdom ${ }^{6} \mathrm{~S} c h o o l$ of International Development and Global Studies, University of Ottawa, Ottawa, Canada
}

Corresponding Author:

Joseph K.Assan

Email: 'joeassan@brandeis.edu
\end{abstract}

(C) 2020 Joseph K. Assan et al. This is an open access article distributed under the terms of the Creative Commons Attribution License, which permits unrestricted use, distribution, and reproduction in any medium, provided the original author(s) and source are credited. 
and marginalized children and improve sanitation and health facilities that are not directly associated with the MDM program. The study concludes that the foundation's MDM programs could serve as a model for an inclusive and nondiscriminatory school feeding system where all children, will equally benefit with dignity. Such an approach, we argue, could also enhance structural equity, youth development, and the attainment of the SDG targets in India.

\section{Keywords}

India, Uttar Pradesh, midday meal, school feeding program, equity, well-being, social inclusion, Dalit, SDGs.

\section{Introduction}

Improving and ensuring access to education for children from low social, economic, caste, ethnic, and other marginalized backgrounds has increased in importance in the academic and policy discourse. This view is also considered to be critical for the attainment of the key educational and human development/dignity targets of the United Nations Global Sustainable Development Goals (SDGs). The provision of educational resources including school lunches to children from deprived and marginalized groups could have a significant impact on their educational performance, school participation, and socio-economic development (Drake et al, 2017). Drake et al. argue that such programs could gain 0.5-2.5 extra years in school and increase income and individuals' future earning potential by five per cent (Ibid).

Nevertheless, it is argued that the implementation of such programs by government and local agencies is, unfortunately, influenced by stereotypical norms used to reinforce discriminatory attitudes and values which then defeat their purpose. Nakkeeran et al. (2020) provide an ethnographic analysis of how the pre-school Supplementary Nutrition Program in India is fraught with institutional barriers and sociological processes that result in the exclusion of families and children from Dalit, lower caste, ethnic and religious minority households from accessing these essential services. The purpose of this study is to conduct an assessment of the performance of an internationally funded Indian foundation and non-government organization (NGO) as Midday Meal (MDM) school feeding program implementers in contributing to the programs' objectives, including equal access to high-quality nutritious meals by children from Dalit, lower caste, ethnic and religious minority, deprived and marginalized households with low social and economic status within public (government-funded) schools in Lucknow, the capital of India's most populous state of Uttar Pradesh. Thorat (2020) argues that although the caste system seems to have diminished or waned in several aspects of societal life, some of its worst features persist. He refers to human development indicators such a per capita income, poverty, malnutrition, education, and assets ownership to illustrate the persistence of inter-caste inequalities and the practice of caste discrimination (Ibid, 2020).

In 2001, the Supreme Court of India mandated that all primary and upper primary school children in government-sponsored and partly sponsored schools shall be provided a midday meal. The School Lunch Program, popularly known as the Midday Meal program, was previously known as the 'National Program for Nutrition Support to Primary Education' (NP-NSPE). It was piloted in 1960 in select states to alleviate 
malnourishment and illiteracy, and has subsequently been expanded nationwide (Chutani, 2012). Its scope was also broadened to include children in upper primary school, thus, making it one of the largest food and nutrition assistance programs in the world (Ibid, 2012).

Several international development organizations and foundations are partnering with the Indian government through public-private partnerships schemes to achieve the objectives of this program. These include increasing school enrolment; increasing school attendance, reducing school dropout rate; and improving the performance of students in class with respect to attention span and academic progress, and finally to improve the nutritional status of participating school children.

This paper offers conclusions in response to two cardinal research questions. First, we seek to ascertain whether the beneficiaries of the MDM program (participating schoolteachers and pupils) International and the World are satisfied with its delivery. Second, whether the MDM scheme has achieved its primary objectives to increase the beneficiaries' school participation and improve their nutritional status. The paper has five sections. Section One outlines the aims and scope of the study, as well as a brief synthesis of previous studies on the MDM scheme whilst Section Two, outlines the methodology and the analytical processes employed to examine the empirical data. Sections Three and Four present the results of the bivariate and multivariate analysis for both teachers and students while Section Five examines the findings to provide the study's conclusions and strategic recommendations.

The overarching goal of MDM, as outlined by the Indian government, is to reduce malnutrition among children of school-going age and improve school enrolment and attendance. These goals, as well as others in the core objectives of the program, are outlined by Chutani (2012) in seven cardinal issues: The program seeks to improve the nutritional status of children and protect them from classroom hunger thus addressing the problem of malnutrition. It is also expected to help increase school enrolment and promote regular school attendance, especially to encourage children belonging to disadvantaged sections of the society. Furthermore, it is expected to provide nutritional support to children of primary school classes in drought-affected areas during summer vacation. The feeding process within the school setting is also likely to improve socialization among children belonging to all castes thus helping to undermine caste prejudices by teaching children to sit together and share a common meal. Thus, the school lunch program acts as a strong social equalizer by reducing the gender gap in school participation. There is also the expectation of creating social empowerment through the provision of employment to women from lower social status and castes and liberate working women from the task of having to feed children at home during the day. Finally, it is anticipated to serve as a source of economic support for the poorer sections of society, particularly Dalits, lower caste, ethnic and religious minority households, and also impart nutrition education to children.

Nevertheless, previous evaluations of the MDM program have focused on the assessment of the different approaches towards the implementation of the program and its achievements. Some such implementation studies have been carried out in Delhi, Uttar Pradesh, Chhattisgarh, Rajasthan, and in Karnataka states (Deshpande, Baru, and Nundy, 2014; Ali and Akbar, 2014; Dreze and Goyal, 2003; the Government of India, 2013; CUTS International and the World Bank, n.d.; State Council for Educational Research and Training (SCERT), 2014). Applying both quantitative and qualitative methods, these studies interview students, teachers, parents, and other 
stakeholders related to the MDM scheme, to ascertain if the implementation fulfills their expectations. Some of the topics covered by these studies include the quality, taste, quantity, and variation of the foods served; as well as hygiene and inclusiveness of the serving process.

In general, the findings of these studies suggest that a majority of the students and program stakeholders are satisfied with the quality of MDM food (Deshpande, Baru, and Nundy, 2014; Dreze and Goyal, 2003; CUTS International and the World Bank, n.d.; SCERT, 2014). However, some concerns expressed in other studies include the inadequate quantity of meals and lack of menu variation which are consistently mentioned as major concerns (Deshpande et al, 2014; Ali and Akbar, 2014; SCERT, 2014). Hygiene is also a common issue. This tends to relate to the absence of handwashing facilities, the availability of a decent source of drinking water, and the use of adequate and appropriate eating utensils during the meal-serving time (Government of India, 2013; CUTS International and the World Bank, n.d.). Also, while open castebased discrimination is rare, some reports have highlighted the incidence of caste resistance towards Dalit cooks (Dreze and Goyal, 2003; CUTS International and the World Bank, n.d.).

Furthermore, some evaluation studies have sought to understand the influence of the MDM program on students' nutritional intake and status, motivation, school attendance, as well as school achievement. For example, the Government of India's study in Uttar Pradesh in 2013 found that students receiving MDM in that state, in general, have a lower nutritional status. However, almost all MDM studies probing impact on nutritional status conclude that MDM can be associated with better nutritional intake and status of the students (Laxmaiah et al., 1999; Afridi, 2010; Sharma, Singh, Meena, and Kannan, 2010; Singh, Park, and Dercon, 2013;).

Moreover, with regard to school participation, interviews with parents or teachers reveal that MDM has helped them in motivating the students to participate more regularly in their school activities (Dreze and Goyal, 2003; Jain and Shah, 2005; Deshpande, Baru, and Nundy, 2014;). Using various quantitative methods, some researchers established an association between MDM program and higher school enrolment and attendance (especially for girls), as well as better school achievement (higher probability to finish school and secure better grades) (Laxmaiah et al., 1999; Dreze and Kingdon, 2001; Afridi, 2011).

\section{Study Background and Methodology}

\section{Study Background: Description of Uttar Pradesh (U.P.)}

Located in the northern part of the country, Uttar Pradesh is India's most populous state and home to 200 million people of whom 60 million are poor (World Bank, 2016a). According to the Census (2011), more than seventy seven percent of the state population still resides in rural areas. While U.P. spends approximately US\$ 59.8 billion on the development of the state (PRS Legislative Research, 2017), with large portions spent on health, sanitation, education, youth employment, agriculture, and rural development, it remains home to the largest number of India's poor (World Bank, 2016b).

According to the National Family Health Survey (NFHS-4) 2015-16 (Ministry of Health and Family Welfare, (2015), U.P. has the worst record in the country for infant 
and under-five mortality. The infant mortality rate (IMR) in the state is 64 per 1,000 while the under-five mortality rate (U5MR) is as high as 78 compared to the national averages of 34 (PIB-Ministry of Health and Family Welfare, 2016) and 43 (World Bank, 2016b), respectively. The report also shows poor vaccination numbers in the state where one in two children is not fully immunized. U.P. also has the country's second-highest Maternal Mortality Rate (MMR) with only 26.4 percent of expecting mothers having access to at least four antenatal care visits (NFHS-4 2015-16). The state has a severe child malnutrition problem, an alarming 63.2 percent of children between six and fifty-nine months are anaemic. Rural-out migration of young people and youth has subsequently become a major concern (Assan and Hill, 2011).

The state also fares low in other indicators like access to clean drinking water and toilet facilities. A report by Tiwari \& Nayak (2013) shows that as much as ninety percent of the households in U.P. do not have access to tap water; and while 34.9 percent of urban households have access to piped drinking water, only two percent of rural households have the same facility albeit relying on other sources (tubewell/ handpump/well/surface water). Additionally, NFHS-4 (2015-16) shows that in U.P. only 23.2 percent of households in rural areas have access to improved sanitation facilities (flush to-piped sewer system, septic tank, pit latrine; ventilated improved pit/ biogas latrine, and composting toilet) and 37.7 percent to electricity.

\section{Study Design}

The study aims to evaluate the implementation of the local foundation's Midday Meal (MDM) program in Lucknow. The study sample consists of students and teachers from Dalit, lower caste, ethnic, and religious minority households in governmentfunded schools covered by the program to ascertain the perspectives of the program's stakeholders.

Several methods were applied to assess program performance. First, close-ended questions were put to respondents to measure their satisfaction level with the program. Some of the program's aspects covered in the questionnaire included quality of meal (general quality, taste, flavor, presentation, variety), the quantity of meal/potion served (general quantity, freedom to ask more, quantity per week), serving process (server attitude, personnel handling the foods, inclusiveness, serving order, temperature, hygiene), and time arrangement (serving time, time allocation, punctuality). A set of close-ended questions on respondents' perceptions of the program's motivational impact was also included. Several different scales were implemented in the closedended questions. Questions regarding program satisfaction used either a fourscale (poor, good, very good, excellent) or three-scale (not satisfied, satisfied, very satisfied) satisfaction measurement. The motivational impact questions applied fourscale possible responses including the very small, small, large, and very large extent of the motivational impact.

Second, open-ended questions on concerns and suggestions were used to collect respondents' inputs for further program improvement. Third, interviewers were also instructed to conduct simple observation on food distribution and eating process in some of the sampled schools. This study is a part of bigger research evaluating the program's impact on nutritional status (anthropometric measurement and other physical characteristics) ${ }^{1}$, attendance rate, and school achievement (subject-based grades). Thus, information on these subjects was also collected along with demographic status and food intake at home. 


\section{Sample Size and Selection Method}

The study generated a sample size of 1,338 Dalit, lower caste, ethnic, and religious minority students in public schools within the Lucknow area, during July-October 2016. The sampling method was clustered random sampling with the school as the cluster unit. The survey included sixty-two schools and interviewed twenty-two Dalit, lower caste, ethnic, and religious minority students per school on average. However, the variation of cluster size is quite big (a standard deviation of 8.74) due to a large variation of the number of students per school.

Allowing for a design effect of two, a clustered sample size of 1,189 should be enough for the study to detect a one per cent proportion/prevalence of a certain event, with a ninety five percent level of confidence and around eighty percent margin of error (or about 0.8 percentage point in absolute term). The usual benchmark for the nutritional study is three percent based on the cut off percentile generally used in determining malnutrition status. ${ }^{2}$ However, no specific benchmark has been advised for the food policy satisfaction level. Thus, a fifty percent prevalence is commonly used. Since a sample size of 1,189 should be good enough to detect a one percent prevalence of any event, the 1,338-sample size should be more than sufficient to provide a precise detection of the research interest (Ahmed, 2009; Charan, \& Biswas, 2013).

However, since the main research object is the students, teachers were not sampled in the same way. About two to three teachers were chosen per school and interviewed. The study ended up with 175 teachers representing all schools. This sample size is good to detect the prevalence of any event of about four percent with a hundred percent margin error, under a ninety five percent level of confidence.

\section{Data Analysis Strategy}

This study employs various data analysis strategies. First, a statistical descriptive analysis is employed to discover the satisfaction level of the respondents, both students and teachers, in various aspects (Assan and Kharisma, 2019). The analysis is grouped based on the categories of questions: food quality, food quantity, serving process, and time arrangement. The analysis uses the proportion of respondents' responses based on the satisfaction scale. When four-scale and three-scale questions are analyzed together, 'poor' is treated as the equivalent of 'not satisfied', 'good' is the equivalent of 'satisfied', and 'very good' and 'excellent' are considered equivalent to 'very satisfied' (Moustakas, 1994).

Second, a qualitative analysis is conducted along with quantitative descriptive analysis. The quantitative analysis categorizes and summarizes the concerns and suggestions based on the categorization used in the descriptive analysis. The prevalence rate of certain suggestion categories is also shown to emphasize the importance of the recommendations.

Third, a multivariate analysis is employed for a deeper understanding of: (1) the determinants of respondents' satisfaction level and tendency to provide suggestions, and (2) the characteristics of respondents, especially those who felt less satisfied and gave more suggestions. By understanding this information, this study tries to define the urgency level and potential benefit of certain program/policy improvements.

Two sets of equations, one for students [equation (1) and (2)] and another set for teachers[equation (3) and (4)], will be used for the multivariate analysis: 


$$
\begin{aligned}
& \text { SSat }_{i}=\gamma_{0}+\gamma_{1}{ }^{\prime} N S_{i}+\gamma_{2}{ }^{\prime} S P_{i}+\gamma_{3} S M I_{i}+\gamma_{4} F_{i}+\gamma_{5} Z_{i}+\gamma_{6}{ }^{\prime} A_{i}+v_{i} \\
& \text { SSug }_{i}=\partial_{0}+\partial_{1} S S a t_{i}+\partial_{2}{ }^{\prime} N S_{i}+\partial_{3}{ }^{\prime} S P_{i}+\partial_{4} S M I_{i}+\partial_{5} F I_{i}+\partial_{6} Z_{i}+ \\
& \partial_{7}{ }^{\prime} A_{i}+u_{i} \\
& \text { TSat }_{i}=\alpha_{0}+\alpha_{1} Z_{i}+\alpha_{2} \text { TMI I }_{i}+\alpha_{3}{ }^{\prime} T_{i}+\varepsilon_{i} \\
& \text { TSug }_{i}=\beta_{0}+\beta_{1} \text { TSat }_{i}+\beta_{2} Z_{i}+\beta_{3} T M I_{i}+\beta_{4}{ }^{\prime} T_{i}+\theta_{i}
\end{aligned}
$$

SSat/TSat : students'/teachers' satisfaction level

SSug/TSug : students'/teachers' number of suggestions given

'NS : : a vector consisting of indicators of students' nutritional status

'SP : a vector consisting of indicators of students' school performance

SMI/TMI : students'/teachers' perception of the program's motivational impact FI

: students' foods intake (number of meals) at home

\section{: zone/location of the school}

Several measures are used to represent students' and teachers' satisfaction level: satisfaction on quantity-related aspects, satisfaction on quality-related aspects, and general satisfaction on all aspects. All satisfaction measures are in the form of composite indicators produced by factor analysis. ${ }^{3}$ The suggestion indicator is in the form of the continuous variable describing the number of concerns and recommendations provided by each respondent.

The vector of nutritional status indicators consists of a composite indicator of anthropometric-based nutritional status ${ }^{4}$, MUAC for height ${ }^{5}$, fainting experience, as well as an indicator of skin, hair, and stomach condition. All nutritional status indicators are in a negative direction, showing higher values when the nutritional status is low. The vector of students' performance consists of students' number of attending days in the week preceding the survey and a composite indicator of students' last performance (self-report, four scales: below average, average, very good, excellent) on Mathematics, Science, Hindi, and their best subjects.

The perception of the program's motivational intake is a composite indicator of students' and teachers' opinions on whether the program had increased students' motivation in attending school, participating in school's physical activities, as well as doing and concentrating better in class. The zone variable describes the school location among four zones served by the organization, namely Chinhat, Kakori, Sarojni Nagar, and Mohanlalganj. Students' control variables include age, gender, grade, guardians' employment status, birth order, and the number of siblings. Teachers' control variables include age, gender, rank/position, and the length of teaching in the current school.

Ordinary least square (OLS) approach is applied for all equations. For the factor analysis, the tetrachoric correlation approach is used to create the anthropometricbased nutritional status composite indicator, since all indicators in this theme are binary. For other composite indicators, including satisfaction level, students' subject grades, perception of motivational and impact, polychoric correlation is applied. Polychoric correlation is more appropriate for categorical variables with more than two categories. Stata is used for all the quantitative data analysis, including the module of tetrachoric and polychoric for the factor analysis. 
Lastly, the study provides an analysis of the program and policy recommendations for improvement. Information gathered from the interviewers' observations is mostly employed in this part, especially regarding the food serving process.

\section{Analysis and Results}

\section{Results from the Descriptive Analysis}

The interviewed students consisted of fifty nine percent females. Most of them were aged between ten and thirteen years, with an average age of 11.36 years (standard deviation of 2.06). About fifty three percent of respondents were students in a five grade lower-primary school, and the rest were three-grade upper-primary school pupils. Almost eighty percent of student respondents tend to belong to the highest grade in their schools- grades four and five for lower primary school and grades seven and eight for upper primary school. The teacher respondents consisted of seventy eight percent females. A little more than half of them were forty years old or more, and on average, they had taught in the current school for 7.19 years (standard deviation of 7.08). About twenty-three percent of the interviewed teachers had senior positions, such as headmaster, headmistress, principal, or the head-teacher. Among the four served zones, in Mohanlalganj teachers were the most represented (thirty one percent) while in Kakori students were the most interviewed (thirty percent).

In general, students' and teachers' satisfaction with the midday meal program operated by the foundation is high. In all aspects, more than ninety percent of respondents expressed their satisfaction. However, respondents have expressed their dissatisfaction more in some specific areas than in others, such as food taste, menu variation, and quantity, as well as serving area hygiene.

\section{Quality, Flavor, and Taste of Food Served}

In terms of general quality, flavor, and taste pupils show a slightly higher dissatisfaction compared to teachers. About three to five percent of pupils rated the food quality, flavor, and taste as 'poor', while only one to three percent of the teachers thought so. However, students were significantly more likely to say that the meals were very good or excellent when compared to teachers, in terms of quality, taste, and flavor (Figure 1).

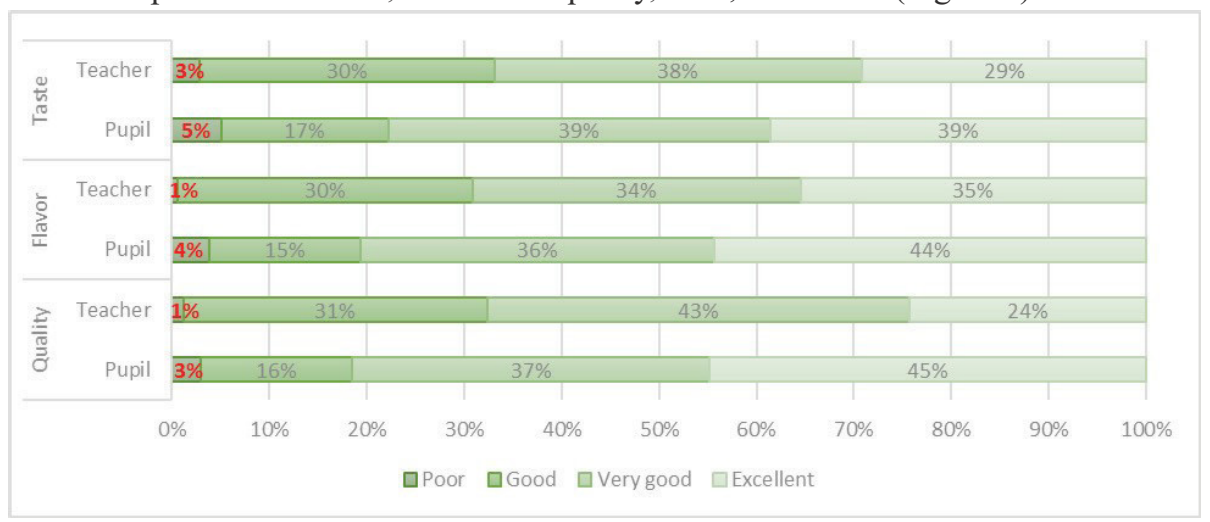

Fig. I: Perception of General Quality, Flavor, and Taste of MDM 
In terms of food presentation, students and teachers were consistently satisfied although menu variation seemed to be a significant concern. Among both pupils and teachers, nine percent expressed their dissatisfaction with the menu variation. This is the highest dissatisfaction rate compared to the other aspects of the program. It is also the only area with negative perception far above five percent in both respondent groups (Figure 2).

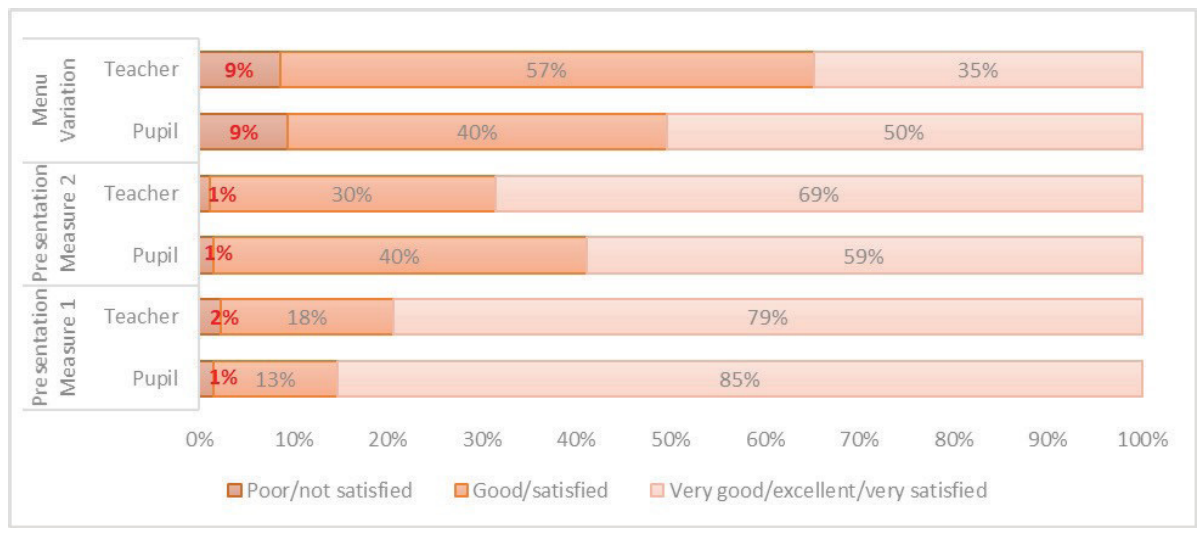

Fig. 2: Perception of the Food Presentation and Menu Variation

Source: Field survey

While the respondents' perception of the food quality is in general positive, the percentage of respondents who provide suggestions related to food quality improvement is quite large. Among the students, six percent provided suggestions related to quality, nine percent mentioned recommendations on taste and flavor improvement, and twenty seven percent suggested options for increasing menu variation. This accounts for up to two-thirds of a total of the 542 students who provided any suggestions. Teachers were more active in terms of providing their suggestions. About thirty four percent of them provided suggestions on quality improvement, twenty seven percent recommended taste or flavor enhancement, and fifty six percent advised better menu variation (Figure 3).

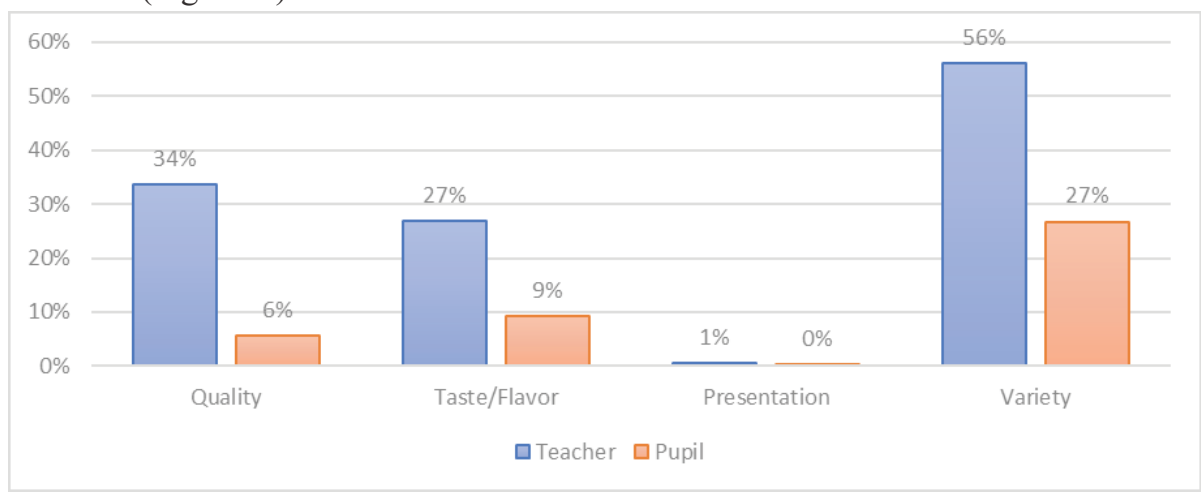

Fig. 3: Percentage of Students and Teachers Giving Quality Improvement Suggestions Source: Field survey 
In terms of content, both students and teachers generally provided similar types of suggestions. For quality improvement, both groups of respondents suggested that chapatis (traditional wheat flour bread baked on a griddle), rice, and vegetables should be cooked more properly, indicating that there were some events when the food served was undercooked (the chapatis were too hard, etc.). Some suggestions also included requests to provide fresher and better-quality fruits. Regarding taste and flavor, a significant number of suggestions stressed the need to improve the taste, especially by adding salt and spices. Teachers were more specific and listed vegetables, curry rice, and soybeans as dishes in which flavor needed to be enhanced. For menu variation, both teachers and students requested more variety of fruits and vegetables. Some popular traditional dishes such as cheese/paneer, chola, Bengal, gram, kadhi chawal, and poori, and also sweets and milk were added to their respective wish lists.

\section{Quantity of Food}

In contrast to food quality, taste, and flavor, students seemed less concerned as compared to teachers about the quantity of meal served. While five percent of teachers expressed their dissatisfaction only two percent of students did not find the quantity adequate. The gap is wider when the question was about 'amount of the foods weekly,' to which six percent of teachers but only one percent of students stated their disappointment. Students show a slightly higher rate of dissatisfaction only under the topic of 'ability to ask for more', even though in general respondents are very satisfied with this aspect (Figure 4).

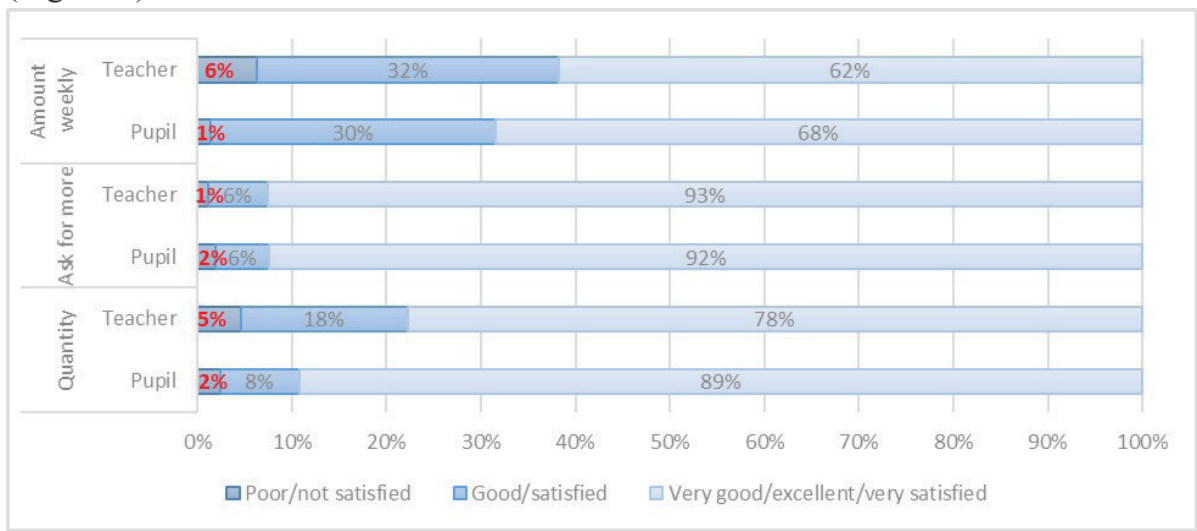

Fig. 4: Perception of Quantity-Related Aspects

Source: Field survey

The same pattern is seen in the subsequent suggestion as well. Only about two percent of students mentioned that the quantity of food served needed to be increased while almost nine percent of teachers suggested more food quantity.

\section{Serving Process}

Both students and teachers mostly expressed high satisfaction over the serving process. Regarding server attitude, inclusiveness, personnel handling the food, and order of serving, only less than one percent among the respondent groups felt dissatisfied. However, the respondents expressed higher concern about the hygiene of the serving 
area, the temperature of food served, the distribution process, and the availability of proper eating/serving utensils (Assan and Chambers, 2014) (Figure 5).

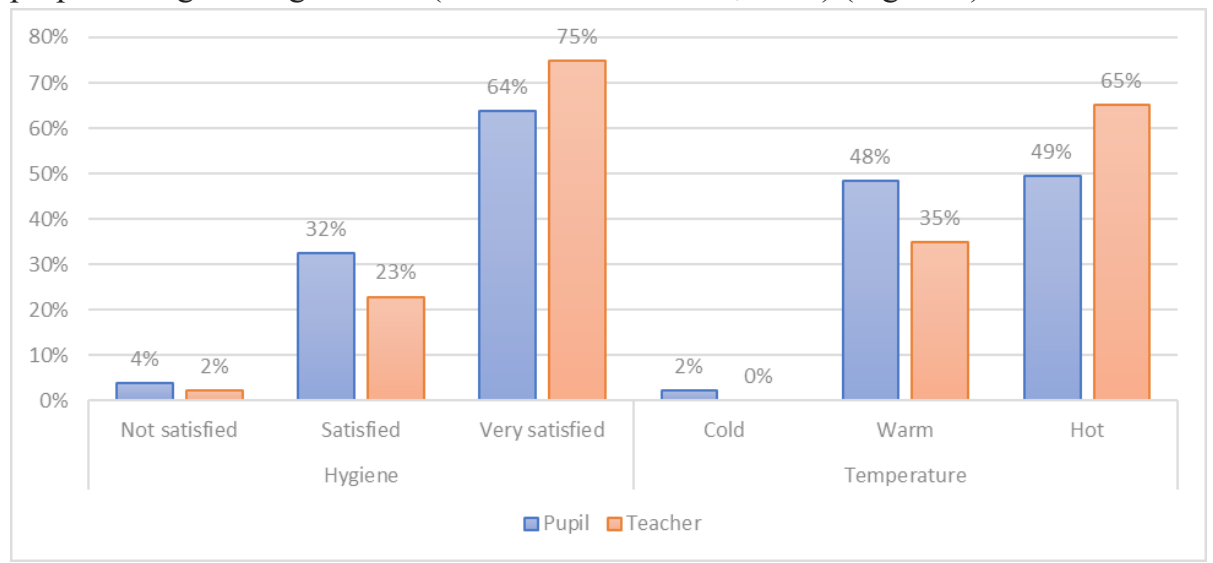

Fig. 5: Perception of Hygiene in the Serving Area and Temperature of Food Served

Source: Field survey

In terms of hygiene of the serving area, students are more concerned than teachers. About four percent of pupils mentioned that hygiene in the serving area is poor, which is almost twice as compared to two percent of teachers who found the hygiene of the area wanting. Students were also less likely than teachers to be very satisfied with the level of hygiene of the area. Students' suggestions on hygiene were mainly asking for a cleaner eating area. Interestingly, teachers' hygiene-related concerns were mostly regarding the cleanliness of the serving utensils rather than the eating area.

As regards food safety, students showed more concern than teachers. While none of the teachers felt that the food served was cold, two percent of students said that the food was served cold. About half of them considered that the food was warm as compared to a significant sixty five percent of teachers who felt that the served food was hot. Thus, no suggestion on this count was forthcoming from teachers regarding temperature, while one percent of students suggested that the food served could be hot or hotter.

Finally, regarding the distribution process, a few teachers hinted that servers were needed because, at present, students were serving themselves under the supervision of teachers. While hardly any students were concerned about utensils, a significant number of teachers suggested the need for providing eating utensils. About fourteen percent of teachers proposed that the program should also offer plates and spoons.

\section{Time Arrangement and Punctuality}

Satisfaction regarding the time of serving food was over ninety eight percent in both respondent groups. Only about one percent of pupils and teachers had concerns about the serving time. About one percent of students and two percent of teachers expressed their dissatisfaction with the time allocation for eating, implying that a longer eating period is needed.

In general, respondents' satisfaction with the punctuality of food arrival at school is high. Only very few students and teachers suggested that food must arrive on time at the schools. When asked to elaborate, at least seventy seven percent of students and 
eighty six percent of teachers said that the arrival of food was never delayed. However, thirteen to fourteen percent of teachers and fifteen to sixteen percent of students acknowledged that arrival of food was delayed at least once in a week, while six percent of students pointed that arrival of food was delayed twice in a week (Figure 6).

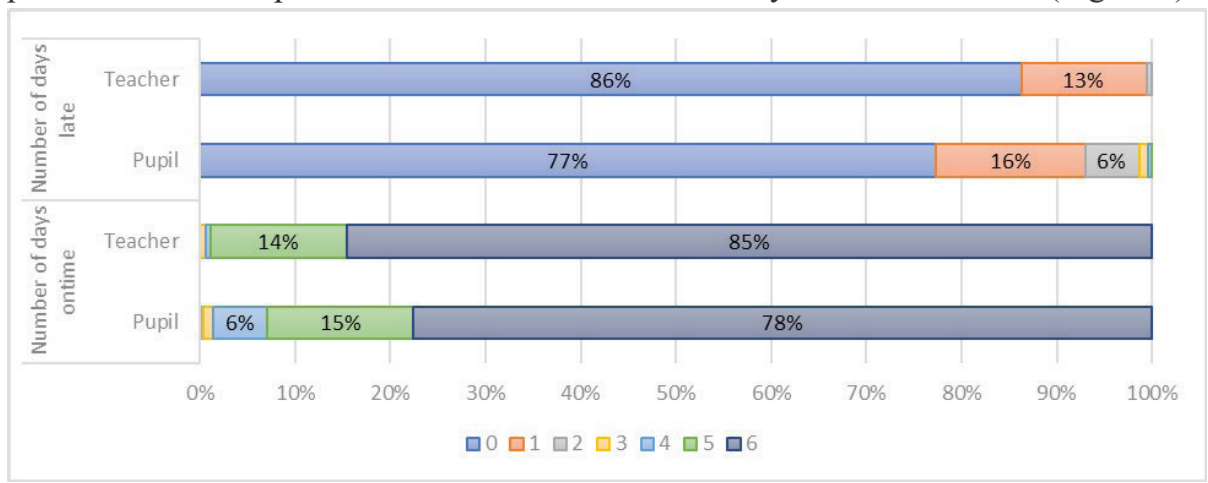

Fig. 6: Perception of Punctuality Regarding the Arrival of Meals at Schools

Source: Field survey

\section{Multivariate Analysis}

The multivariate analysis suggests that there were some strong determinants of students' satisfaction and likelihood to provide a higher number of suggestions for the MDM program. Students' nutritional status significantly influenced their satisfaction with the program. Students with an indication of stomach protrusion (a sign of malnutrition) were significantly more likely to be satisfied with the feeding program, either in terms of quantity, quality, or general satisfaction. However, students with unhealthy hair, or skin showed different tendencies. These students are significantly more likely to be dissatisfied with the program.

Table I: Regression analysis on students' satisfaction and number of suggestions

\begin{tabular}{|c|c|c|c|c|}
\hline & $\begin{array}{c}\text { I } \\
\text { Satisfaction on } \\
\text { Quantity }\end{array}$ & $\begin{array}{c}\text { II } \\
\text { Satisfaction on } \\
\text { Quality }\end{array}$ & $\begin{array}{c}\text { III } \\
\text { General } \\
\text { Satisfaction }\end{array}$ & $\begin{array}{c}\text { IV } \\
\text { Number of } \\
\text { Suggestion } \\
\text { Given }\end{array}$ \\
\hline \multicolumn{5}{|l|}{ Nutritional Status } \\
\hline \multirow{2}{*}{$\begin{array}{l}\text { Low anthropometric- } \\
\text { based nutritional } \\
\text { status }\end{array}$} & 0.047 & 0.007 & -0.018 & 0.057 \\
\hline & {$[-0.040,0.133]$} & {$[-0.100,0.114]$} & {$[-0.101,0.065]$} & {$[-0.043,0.157]$} \\
\hline \multirow{2}{*}{$\begin{array}{l}\text { MUAC for height } \\
\text { lower than }-2 \text { std. dev. }\end{array}$} & -0.022 & 0.039 & 0.021 & -0.048 \\
\hline & {$[-0.096,0.052]$} & {$[-0.052,0.130]$} & {$[-0.050,0.091]$} & {$[-0.133,0.038]$} \\
\hline \multirow[t]{2}{*}{ Unhealthy hair } & $-0.080 *$ & -0.069 & $-0.077^{*}$ & $0.092 *$ \\
\hline & {$[-0.145,-0.016]$} & {$[-0.149,0.010]$} & {$[-0.138,-0.015]$} & {$[0.017,0.166]$} \\
\hline \multirow[t]{2}{*}{ Unhealthy skin } & $-0.138 * * *$ & $-0.140 * * *$ & $-0.177^{* * *}$ & $0.099 *$ \\
\hline & {$[-0.205,-0.07 I]$} & {$[-0.222,-0.057]$} & {$[-0.240,-0.113]$} & {$[0.021,0.178]$} \\
\hline \multirow{2}{*}{$\begin{array}{l}\text { Indication of stomach } \\
\text { protrusion }\end{array}$} & $0.155 * *$ & $0.162 *$ & $0.243 * * *$ & 0.017 \\
\hline & {$[0.051,0.258]$} & {$[0.034,0.290]$} & {$[0.144,0.342]$} & {$[-0.104,0.138]$} \\
\hline
\end{tabular}




\begin{tabular}{|c|c|c|c|c|}
\hline & $\begin{array}{c}\text { I } \\
\text { Satisfaction on } \\
\text { Quantity }\end{array}$ & $\begin{array}{c}\text { II } \\
\text { Satisfaction on } \\
\text { Quality }\end{array}$ & $\begin{array}{c}\text { III } \\
\text { General } \\
\text { Satisfaction }\end{array}$ & $\begin{array}{c}\text { IV } \\
\text { Number of } \\
\text { Suggestion } \\
\text { Given }\end{array}$ \\
\hline \multicolumn{5}{|l|}{ Nutritional Status } \\
\hline \multirow{2}{*}{$\begin{array}{l}\text { Fainting experience } \\
\text { last week }\end{array}$} & -0.002 & 0.034 & 0.017 & 0.078 \\
\hline & {$[-0.087,0.083]$} & {$[-0.070,0.139]$} & {$[-0.064,0.098]$} & {$[-0.020,0.176]$} \\
\hline \multicolumn{5}{|l|}{ School performance } \\
\hline \multirow{2}{*}{$\begin{array}{l}\text { Number of attendance } \\
\text { days last week }\end{array}$} & $0.033 * *$ & $0.048 * *$ & $0.047 * * *$ & -0.008 \\
\hline & {$[0.009,0.057]$} & {$[0.019,0.078]$} & {$[0.024,0.070]$} & {$[-0.036,0.020]$} \\
\hline \multirow[t]{2}{*}{ Performance in class } & 0.02 & 0.019 & 0.01 & 0.033 \\
\hline & {$[-0.020,0.060]$} & {$[-0.030,0.069]$} & {$[-0.028,0.048]$} & {$[-0.013,0.080]$} \\
\hline \multirow[t]{2}{*}{ Age } & 0.008 & -0.008 & 0.01 & -0.006 \\
\hline & {$[-0.018,0.033]$} & {$[-0.039,0.024]$} & {$[-0.0 \mid 4,0.034]$} & {$[-0.035,0.024]$} \\
\hline \multirow[t]{2}{*}{ Grade } & 0.012 & -0.002 & 0.006 & 0.016 \\
\hline & {$[-0.0 \mid 4,0.038]$} & {$[-0.035,0.030]$} & {$[-0.019,0.031]$} & {$[-0.014,0.047]$} \\
\hline \multirow[t]{2}{*}{ Male } & -0.011 & -0.04 & -0.032 & -0.052 \\
\hline & {$[-0.074,0.053]$} & {$[-0.118,0.039]$} & {$[-0.093,0.029]$} & {$[-0.125,0.022]$} \\
\hline \multirow{2}{*}{$\begin{array}{l}\text { Guardians work in } \\
\text { agricultural sector }\end{array}$} & 0.064 & $0.104 *$ & $0.132 * * *$ & -0.048 \\
\hline & {$[-0.009,0.137]$} & {$[0.015,0.194]$} & {$[0.063,0.201]$} & {$[-0.132,0.036]$} \\
\hline \multirow{2}{*}{$\begin{array}{l}\text { Number of meals } \\
\text { received at home }\end{array}$} & $0.133 * * *$ & $0.20 \mathrm{I} * * *$ & $0.147^{* * * *}$ & 0.035 \\
\hline & {$[0.084,0.182]$} & {$[0.140,0.261]$} & {$[0.101,0.194]$} & {$[-0.023,0.093]$} \\
\hline \multirow[t]{2}{*}{ Order of birth } & 0.021 & 0.018 & 0.017 & $-0.034 *$ \\
\hline & {$[-0.002,0.044]$} & {$[-0.011,0.047]$} & {$[-0.006,0.039]$} & {$[-0.061,-0.007]$} \\
\hline \multirow[t]{2}{*}{ Number of siblings } & -0.016 & -0.027 & -0.011 & $0.034 *$ \\
\hline & {$[-0.043,0.012]$} & {$[-0.061,0.007]$} & {$[-0.037,0.015]$} & {$[0.002,0.066]$} \\
\hline \multirow{2}{*}{$\begin{array}{l}\text { Perception on MDM } \\
\text { motivational impact }\end{array}$} & $0.127 * * *$ & $0.169 * * *$ & $0.119 * * *$ & 0.042 \\
\hline & {$[0.084,0.171]$} & {$[0.116,0.223]$} & {$[0.078,0.161]$} & {$[-0.010,0.093]$} \\
\hline \multirow[t]{2}{*}{ Location in Chinhat } & $-0.475 * * *$ & $-0.639 * * *$ & $-0.599 * * *$ & $-0.302 * * *$ \\
\hline & {$[-0.574,-0.376]$} & {$[-0.761,-0.516]$} & {$[-0.694,-0.505]$} & {$[-0.425,-0.179]$} \\
\hline \multirow[t]{2}{*}{ Location in Kakori } & $-0.234 * * *$ & $-0.459 * * *$ & $-0.340 * * *$ & $-0.436 * * *$ \\
\hline & {$[-0.322,-0.146]$} & {$[-0.568,-0.350]$} & {$[-0.424,-0.255]$} & {$[-0.541,-0.330]$} \\
\hline \multirow{2}{*}{$\begin{array}{l}\text { Location in Sarojni } \\
\text { Nagar }\end{array}$} & 0.051 & $-0.297 * * *$ & $-0.157 * * *$ & -0.076 \\
\hline & {$[-0.037,0.138]$} & {$[-0.405,-0.189]$} & {$[-0.240,-0.073]$} & {$[-0.177,0.026]$} \\
\hline \multirow[t]{2}{*}{ General satisfaction } & & & & $-0.319 * * *$ \\
\hline & & & & {$[-0.394,-0.245]$} \\
\hline \multirow[t]{2}{*}{ Constant } & 2.366 *** & $2.736 * * *$ & $2.903 * * *$ & $1.536 * * *$ \\
\hline & {$[1.999,2.733]$} & {$[2.284,3.188]$} & {$[2.553,3.253]$} & {$[1.061,2.011]$} \\
\hline$N$ & 1,040 & 1,038 & 1,037 & 1,037 \\
\hline R-Squared & 0.225 & 0.212 & 0.278 & 0.152 \\
\hline
\end{tabular}

Source: Field data 
Other than nutritional status, guardians' type of job, number of meals received at home, and school location were also significantly correlated with satisfaction levels. Students with guardians working in the agricultural sector tended to be more satisfied with the program. Students who received more frequent meals at home also seemed to be less dissatisfied with meals at schools. In terms of location, students studying in Chinhat and Kakori zones had the highest satisfaction level, while students in Mohanlalganj had the lowest satisfaction level. An observation that is worthy of note is that, students with higher attendance rates and better perception of the program's motivational impact are also those with higher satisfaction levels.

Regarding suggestions, students with unhealthy hair or unhealthy skin, statistically significantly provided more suggestions, keeping other variables constant. While not statistically significant, other nutritional status indicators, except MUAC for height, also indicate that students with lower nutritional status expressed more suggestions. The satisfaction level is proven to be a strong determinant for providing suggestions. A higher satisfaction level is significantly associated with a lower number of suggestions. Also consistent with the regional pattern of satisfaction, students in Chinhat and Kakori who had the highest satisfaction level were also the ones with the lowest number of suggestions. Mohanlalganj students, on the other hand, had both the lowest satisfaction level and the highest number of suggestions (Refer to Table 2).

Table 2: regression Analysis of Teachers' Satisfaction and Number of Suggestions

\begin{tabular}{|c|c|c|c|c|c|}
\hline & \begin{tabular}{|l|} 
Satisfaction \\
on Quantity
\end{tabular} & $\begin{array}{l}\text { Satisfaction } \\
\text { on Quality }\end{array}$ & \begin{tabular}{|c|} 
General \\
Satisfaction I
\end{tabular} & $\begin{array}{c}\text { General } \\
\text { Satisfaction } 2\end{array}$ & $\begin{array}{c}\text { Number of } \\
\text { Suggestions } \\
\text { Given }\end{array}$ \\
\hline \multirow[t]{2}{*}{ Male } & $-0.214^{*}$ & -0.081 & -0.035 & $-0.254^{*}$ & 0.088 \\
\hline & {$[-0.427,-0.002]$} & {$[-0.324,0.161]$} & {$[-0.219,0.149]$} & {$[-0.486,-0.021]$} & {$[-0.260,0.436]$} \\
\hline \multirow{2}{*}{$\begin{array}{l}\text { Number of years } \\
\text { teaching in current } \\
\text { school }\end{array}$} & 0.003 & 0.003 & 0.004 & 0.001 & -0.001 \\
\hline & {$[-0.011,0.018]$} & {$[-0.014,0.019]$} & {$[-0.008,0.016]$} & {$[-0.015,0.017]$} & {$[-0.024,0.022]$} \\
\hline \multirow[t]{2}{*}{ Rank } & -0.003 & -0.012 & -0.034 & 0.127 & 0.221 \\
\hline & {$[-0.2 \mid 4,0.207]$} & {$[-0.249,0.225]$} & {$[-0.2 \mid 4,0.146]$} & {$[-0.100,0.355]$} & {$[-0.117,0.558]$} \\
\hline \multirow[t]{2}{*}{ Age 40+ } & 0.04 & 0.069 & 0.057 & 0.013 & 0.242 \\
\hline & {$[-0.144,0.224]$} & {$[-0.140,0.279]$} & {$[-0.102,0.215]$} & {$[-0.188,0.2 \mid 3]$} & {$[-0.054,0.539]$} \\
\hline \multirow[t]{2}{*}{ Location in Chinhat } & $-0.704 * * *$ & $-0.555 * *$ & $-0.593 * * *$ & -0.19 & $-0.890 * * *$ \\
\hline & {$[-0.994,-0.4 \mid 3]$} & {$[-0.883,-0.228]$} & {$[-0.841,-0.344]$} & {$[-0.504,0.124]$} & {$[-1.384,-0.396]$} \\
\hline \multirow[t]{2}{*}{ Location in Kakori } & $-0.663 * * *$ & $-0.897 * * *$ & $-0.725 * * *$ & -0.174 & $-1.024 * * *$ \\
\hline & {$[-0.896,-0.430]$} & {$[-1.162,-0.633]$} & {$[-0.926,-0.525]$} & {$[-0.427,0.079]$} & {$[-1.453,-0.595]$} \\
\hline \multirow{2}{*}{$\begin{array}{l}\text { Location in Sarojni } \\
\text { Nagar }\end{array}$} & $-0.253^{*}$ & -0.251 & $-0.274 * *$ & -0.137 & -0.348 \\
\hline & {$[-0.480,-0.026]$} & {$[-0.508,0.006]$} & {$[-0.469,-0.079]$} & {$[-0.383,0.110]$} & {$[-0.721,0.025]$} \\
\hline \multirow{2}{*}{$\begin{array}{l}\text { Perception on MDM } \\
\text { motivational impact }\end{array}$} & 0.083 & 0.099 & 0.052 & 0.115 & -0.048 \\
\hline & {$[-0.041,0.207]$} & {$[-0.040,0.239]$} & {$[-0.054,0.158]$} & {$[-0.018,0.249]$} & {$[-0.248,0.151]$} \\
\hline \multirow[t]{2}{*}{$\begin{array}{l}\text { General satisfaction } \\
\text { I }\end{array}$} & & & & & -0.173 \\
\hline & & & & & {$[-0.473,0.126]$} \\
\hline
\end{tabular}




\begin{tabular}{|l|c|c|c|c|c|}
\hline & $\begin{array}{c}\text { Satisfaction } \\
\text { on Quantity }\end{array}$ & $\begin{array}{c}\text { Satisfaction } \\
\text { on Quality }\end{array}$ & $\begin{array}{c}\text { General } \\
\text { Satisfaction I }\end{array}$ & $\begin{array}{c}\text { General } \\
\text { Satisfaction 2 }\end{array}$ & $\begin{array}{c}\text { Number of } \\
\text { Suggestions } \\
\text { Given }\end{array}$ \\
\hline $\begin{array}{l}\text { General } \\
\text { satisfaction 2 }\end{array}$ & & & & & $-0.26 I^{*}$ \\
\hline & & & & & {$[-0.498,-0.024]$} \\
\hline Constant & $3.152^{* * *}$ & $3.38 I^{* * *}$ & $4.073 * * *$ & -0.132 & $2.654 * * *$ \\
\hline & {$[2.709,3.596]$} & {$[2.879,3.883]$} & {$[3.693,4.454]$} & {$[-0.613,0.349]$} & {$[1.234,4.073]$} \\
\hline N & 175 & 173 & 173 & 173 & 173 \\
\hline R-Squared & 0.237 & 0.256 & 0.28 & 0.067 & 0.192 \\
\hline
\end{tabular}

Source: Field data

The same analysis on teachers' data shows considerably consistent results, especially regarding locational patterns and negative correlation between satisfaction level and tendency to provide suggestions. Holding everything else constant, teachers with higher satisfaction levels have statistically significantly provided fewer suggestions. Teachers in Chinhat and Kakori had the highest satisfaction level and lowest number of proposed recommendations, while teachers of Mohanlalganj zone expressed the least satisfaction and highest number of suggestions.

\section{Discussion}

\section{Discussion of Results}

This study managed to analyze satisfaction levels and suggestions of students and teachers from marginalized groups with respect to various aspects of the MDM program in their school supported by the local foundation. In general, the overall satisfaction levels of students as well as teachers were over ninety percent. However, there are some aspects such as taste, quantity, menu variation, and eating area hygiene in which the dissatisfaction level was higher. A deeper analysis of respondents' suggestions helped the study to detect more detailed concerns on these aspects. Furthermore, the multivariate analysis suggested some strong determinants of satisfaction level, such as nutritional status, food intake at home, and school location. The analysis also implied that nutritional status, location, and satisfaction level contributed significantly to the number of suggestions provided by respondents. These are critical to the well-being, attainment of educational goals, participation, and academic improvement of the study sample.

The quality, taste, flavor, and menu variation are the most frequent concerns voiced by the respondents. To address challenges related to quality, taste, and flavor, as much as possible the food served should be consistent with local expectations. For instance, suggestions to add salt and spices, as well as to cook chapatis, rice, and vegetables more properly, should be followed up accordingly. To address challenges pertaining to variety, the program implementers need to expand the menu options and include a wider assortment of fruits and vegetables in their meals, which have been popularly requested. 
Regarding quantity, teachers seemed to be the ones stating greater concern about inadequacy. The number of suggestions to increase the amount of food is not very high among students. However, the multivariate analysis suggests that students with unhealthy hair, unhealthy skin, and fewer meals received at home had a statistically significantly lower satisfaction level on the quantity of food provided through the scheme. This indicates that increasing the quantity of the meals may help Dalit, lower caste, ethnic, and religious minority students, who tend to have lower nutritional status and receive less food intake at home (Nakkeeran, et al., 2020).

In terms of the serving process, the study discovered that students and teachers did not agree on the temperature of the served meals. While students' responses on food temperature varied from warm to cold, most teachers described the meals served as hot. To address this concern in maintaining the temperature of the meals served, the food should be delivered in hot trolleys or and containers which may be plugged into electrical sockets in the school kitchen in ideal situations. The temperature of the food should be noted at the time of departure from the central kitchen in Lucknow and on arrival at the receiving school to ensure that its temperature is within the prescribed range recommended by the World Health Organization (WHO) or the Ministry of Health in India. In the absence of electricity, the food should be transported in appropriate containers and placed on Liquefied Petroleum Gas (LPG) stoves/warmers on arrival in the school. Alternative heating arrangements should be used depending on locally available resources.

Given that Indians culturally tend to eat with their hands, it was striking to observe that a significant number of teachers indicated the need to have spoons, along with utensils. It is important to note that while children currently eat their meals with their hands and do not use cutlery, it is probable that the teachers would prefer to see a shift from this pattern or cultural expectation and practice, given that these meals are being served in a school setting. It could also be an expression of concern as children do not wash their hands at all or do so improperly for want of water. After all, they tend to sit on the ground on what appears to be a dirty floor and surely touch the floor with their hands upon sitting. That would be reason enough to want utensils and even tables that could be cleaned daily. It is important to note that similar requests were also expressed by students, even though their number was fewer compared to teachers.

Besides, the sampled teachers requested better-organized seating arrangements, and the provision of appropriate utensils including spoons, plates, and cutlery. This may seem culturally contradictory, given that it is considered culturally acceptable and common practice to eat by hand in India. It is also probable that the teachers' request for such facilities is to help minimize the possibility of the common pattern of social isolation of Dalit, lower caste, ethnic and religious minority groups as well as redress contamination and infection that occur from children eating with hands that have not been washed properly. This concern is even more urgent given the recent novel COVID-19 pandemic, which is reported by the media to disproportionately affect individuals from lower-social status and poor backgrounds including groups represented by our study sample. It becomes even more significant as states reconsider reopening schools.

Given that handwashing is done voluntarily by students and also depends on the availability of water, improper supervision of handwashing can lead to students contracting diseases like cholera and diarrhea. Such an occurrence could then be wrongfully attributed to the quality of meals rather than the unhygienic handling of 
food by children. Also, hygiene around food service areas needs to be improved. There are reports of flies and other insects hovering around the food preparation and service areas. This particular challenge can be addressed by providing screened areas where food is served and consumed. Implementers can take steps to improve hygiene related to their food service. However, general sanitation in schools is outside the remit of MDM program implementers even though general school hygiene can potentially impact on nutritional and health outcomes of students. Implementing organizations can address some of these external factors by collaborating with appropriate stakeholders such as the municipal councils and the local education department to reduce potential negative impacts on their program.

The present study also makes several noteworthy observations regarding the personnel serving food. One major concern is the lack of Personal Protective Equipment (PPE) such as protective clothing, gloves, and masks for the serving personnel. International hygiene standards require persons who handle food to wear clean protective over-clothing, for example, disposable aprons or overalls. Also, hair should be covered with a hairnet. It was evident that this was not the case in all the schools visited during the field survey. Implementing such protocols would significantly enhance the level of hygiene associated with the management of food at the school level. A reasonable approach to tackle this issue could be to train all personnel responsible for the preparation, handling, and or serving of food in all aspects of food safety and hygiene with emphasis on the hazards and risks involved in food preparation, handling, and service.

Following up on the findings from the multivariate analysis, nutritional status and food intake at home significantly matter in determining students' satisfaction and subsequent suggestions. While students with stomach protrusion tended to be satisfied with the foods and program's general implementation, students with unhealthy hair or unhealthy skin were more likely to have a lower satisfaction rate. The second group was also more likely to provide suggestions. Students who received fewer meals at home had lower satisfaction as well in all aspects. This finding implies that the betteroff students might feel more satisfied because they had lower needs, in terms of food and nutrition intakes. On the other hand, the worse-off students, those with lower nutritional status and fewer meals at home, felt the need to receive more and better meals. Thus, they feel more dissatisfied with what had been served. Improving the quality, quantity, and serving process of the food may then provide larger benefits to the worse-off students.

The analysis finds a strong positive correlation between attendance rate and satisfaction level, as well as motivational impact and satisfaction level. Further research is needed to find out the direction of the causality connection. For instance, it could be either that the highly satisfied students attend school more to get meals, or those who attend school more have a more complete picture of the program and feel more satisfied. If the first scenario was the case, further improving satisfaction levels may be of further help to increase students' attendance rates. Regarding motivational impact, the same analysis applies. It might either be that high satisfaction leads to a higher belief that the program had motivated them in school, or the students felt motivated by the program and expressed their satisfaction more. If the first applies, improving satisfaction may also lead to an improvement in their motivation which is critical for students from low social status and marginalized backgrounds. 


\section{Conclusion and Recommendations for Policy and Practice}

The findings of this study indicate that for all performance indicators including food quality, variety, and presentation, as well as timeliness and overall service delivery, a significant majority of both students and teachers, are extremely satisfied. The local foundation's internationally funded feeding programs have been effective and performed equitably. Our analysis reveals that the non-discrimination model of the internationally funded local foundation is also shown to be a strong factor in students' motivation for school attendance and participation; and therefore effective in improving the well-being of marginalized school children. More than fifty percent of student respondents indicated that MDM played a large or very large role in their school attendance, participation, ability to concentrate in class, and their ability to do well in school. An even larger percentage of teachers (above sixty five percent on all relevant indicators) acknowledged that MDM was a large motivating factor in pupils' school attendance, engagement in physical activities, classroom concentration, and overall performance.

The impact of MDM on nutritional status is relatively difficult to assess due to the absence of reliable baseline data and comparison groups. Nevertheless, we were able to identify reliable data from studies conducted by the Indian Government in Uttar Pradesh and Cross-National Data for India, as sources of comparison with our data. Comparing students in our sample to Indian national averages shows significant proportions of Lucknow students lagging on indicators like height, weight, BMI, mid-upper arm, and waist circumference for age. A small percentage of students also showed evidence of malnourishment such as stomach protrusion and fainting. However, these are more likely to be a function of existing or pre-existing social and economic deprivation due to their socio-economic and cultural status, and the degree of impoverishment present in the districts/resident households represented by the sampled students/schools.

On the contrary, a comparative analysis between our findings and studies by the federal government in U.P. revealed striking results. The analysis shows that while state-runs school students covered by local foundation MDM in Lucknow appeared to have lower nutritional status as compared to national standards, they were much better off when compared to students in other districts of U.P. Comparing disaggregated anthropometric data by age and gender of students from our study sample in Lucknow with students in other districts in the state, we see that across almost all age groups and genders, students in our study sample from Lucknow had higher nutritional status than those from other districts in U.P. This pattern was also consistent with results from our comparison of BMI and MUAC indicators, by age and gender between the two sample groups.

Nevertheless, in spite of the notable success of the local foundation's MDM implementation in Lucknow, there are several changes or improvements that can be made to enhance the program's impact. Teachers made both strategic and logistical recommendations for the advancement of the program. They identified specific areas of concern that could be improved: variety, taste, quantity, and general food quality were most cited by respondents as areas needing improvement. Specific suggestions for improving meals were wide-ranging: they included ideas on how to cook certain dishes (some traditionally sweet dishes were reportedly served salty and vice versa), the use of salt and spices to improve the taste of food, and the inclusion of other foods especially fruits and vegetables. 
In addition to the factors that directly impact the implementation of the local foundation's MDM in Lucknow, there are other external factors that can potentially impact its overall success. Demographic and household characteristics like gender, the number of siblings a student has, the number of meals they have at home, and overall nutritional status affect program satisfaction and its impact on beneficiaries.

Another important finding that requires policy attention is that our analysis revealed that several of the Dalit and lower caste students who have been on the local foundation's feeding program are yet to exhibit positive nutritional improvement. This finding confirms the notion that nutritional programs may take years to have the desired impact on the individuals involved in them. In this case, our study suggests that MDM implementers would have to offer consistent and sustained feeding programs to many of the schools in our sample over a longer period to allow the students to derive the expected benefits of nutrition intervention. This is very important as such an observation could be easily misconstrued to imply a lack of impact, which would be inaccurate. It is particularly important for a state like U.P. where a large proportion of the young population, particularly from Dalit, lower caste, ethnic, and religious minority households have been reported to have low nutritional status (Nakkeeran et al. 2020, Assan and Gupta, 2018).

Above all, such evaluation surveys could serve as baseline data for future longitudinal studies to help track students currently receiving MDM through the local foundation's feeding programs. A comparative study of schools currently receiving MDM through such programs and schools listed to receive MDM through such publicprivate initiatives will also help implementers to develop a new baseline database that could be utilized in assessing school-level performance. It would be interesting to have longitudinal studies that would then track such pupils along their educational paths to ascertain how many of them would progress into further and higher educational institutions.

To conclude, a cardinal value that could be engendered from this study is that the non-discriminatory protocols and approach used by internationally funded foundations and local organizations supported by international donors in their school feeding programs could be emulated as a model in the state government's work towards addressing social exclusion and marginalization associated with the provision of social protection programs and services to poor and low-income households and the wider society (Nakkeeran et al. 2020; Assan and Chambers, 2014). This approach could be particularly helpful for school feeding programs operated by national and local organizations. Also, policy officials and key stakeholders of this initiative are now able to identify and advocate for at-risk children and their households in the sampled schools and beyond. Again, program implementers and funding agencies can collaborate with other development agencies to initiate and coordinate follow up programs for such individuals and their households. This model could ensure scaling up so that the overall impact of feeding children at school would ultimately translate into the attainment of their long-term human development and dignity (Assan and Gupta, 2018). Such an effort would ultimately contribute toward improving the human development index of India and the attainment of local and national targets for 2030 SDGs. Thus, the study demonstrates that enhancing the voice, participation, confidence, dignity, and wellbeing of individuals from low social and economic strata within the Indian society could contribute to overall national development. 


\section{References}

Afridi, F. (2010). Child welfare programs and child nutrition: Evidence from a mandated school meal program in India. Journal of Development Economics, 92, 152-165. DOI: 10.1016/j. jdeveco.2009.02.002

Afridi, F.(2011). The impact of school meals on school participation: evidence from rural India. The Journal of Development Studies, 47(11), 1636-1656. DOI: 10.1080/00220388.2010.514330 Ahmed, S. (2009). Methods in Sample Surveys: Cluster Sampling [PowerPoint slides]. Retrieved from http://ocw.jhsph.edu/courses/StatMethodsForSampleSurveys/PDFs/ Lecture5.pdf

Ali, J. \& Akbar, M. (2015). Understanding students' preferences on school midday meal menu in India. British Food Journal, 117(2), 805-819. DOI: 10.1108/BFJ-03-2014-0099

Assan, J. K.and Hill, H.(2011). Child exploitation and bonded labour in India, Law, Social Justice \& Global Development,16(2), 1-21.

Assan, J. K., and Chambers, T. (2014). India's street vendors and the struggle to sustain their livelihoods and informal enterprises: unionisation, political action, and sustainable development, International Journal of Development and Sustainability, 3(11), 2140-2161.

Assan, J.K., and Gupta, P. (2018). Bridging organizations and innovative sustainable development partnerships, Area Development, and Policy,4(1), 60-80.

Assan, J.K., and Kharisma, D. (2019). Political economy of internal migration and labour seeking behaviour of poor youth in Ghana, Ghana Studies, 22, (University of Wisconsin Press).

Charan, J. \& Biswas, T. (2013). How to calculate sample size for different study designs in medical research? Indian Journal of Psychological Medicine, 35(2), 121-126. DOI: $10.4103 / 0253-7176.116232$

Census (2011). Census of India, 2011. Office of the Registrar General \& Census Commissioner, India, Retrieved from http://censusindia.gov.in/

Chutani, A.M. (2012), School lunch program in India: background, objectives, and components, Asia Pac J Clin Nutr.21 (1): p.151-154.

CUTS International \& The World Bank. (n.d.). Measuring Effectiveness of Midday Meal Scheme in Rajasthan: Participatory Expenditure Tracking Survey. Retrieved from http:// cuts-international.org/pdf/PETS.pdf

Deshpande, M., Baru, R. V., \& Nundy, M. (2014). Re-imagining school health in education and health programmes: a study across selected municipal schools in Delhi. Contemporary Education Dialogue, 11(1), 5-39. DOI: 10.1177/0973184913509751

Drake L., Russo, R., and Defeyter, M.A. (2017). Editorial: The impact of school food consumption on children's cognition, educational attainment, and social development. Front. Public Health5, 204.

Drèze, J. \&Goyal, A. (2003). Future of midday meals. Economic and Political Weekly, 38(44), 4673-4683. Retrieved from http://www.epw.in/journal/2003/44/special-articles/future-midday-meals.html

Drèze, J. \& Kingdon, G. G. (2001). School participation in rural India. Review of Development Economics, 5(1), 1-24. DOI: 10.1111/1467-9361.00103

Government of India. (2013). Report of 5th joint review mission on midday meal scheme: Uttar Pradesh. Retrieved from http://mdm.nic.in/Files/Review/Fifth_Review/UP/Final_Report JRM_UP.pdf

Government of Uttar Pradesh. (2007). The $2^{\text {nd }}$ human development report of Uttar Pradesh.

Retrieved from http://hdr.undp.org/sites/default/files/india_uttar_pradesh_2007.pdf 
Jain, J. \& Shah, M. (2005). Antyodaya anna yojana and midday meals in MP. Economic and Political Weekly, 40(48), 5076-5080+5085-5092, Retrieved from http://www.jstor.org/ stable $/ 4417460$

Khadilkar, V., Yadav, S., Agrawal, K. K., Tamboli, S., Banerjee, M., Cherian, A., Yewale,

V. (2015). Revised IAP growth charts for height, weight, and body mass index for 5- to 18-yearold Indian children. Indian Pediatrics, 52(1), 47-55. DOI: 10.1007/s13312-015- 0566-5

Kuriyan, R., Thomas, T., Lokesh, D. P., Sheth, N. R., Mahendra, A., Joy, R., Kurpad, A. V.(2011). Waist circumference and waist for height percentiles in urban South Indian children aged 3-16 years. Indian Pediatrics, 48(10), 765-771. DOI: 10.1007/s13312-011-0126-6

Laxmaiah, A., Sarma, K.V.R., Rao, D.H., Reddy, G., Ravindranath, M., Rao M.V., \& Vijayaraghavan, K. (1999). Impact of midday meal program on educational and nutritional status of school children in Karnataka. Indian Pediatrics, 36(12), 1221-1228. Retrieved from http://indianpediatrics.net/dec-99/99-dec-3.htm

Mei, Z., Grummer-Strawn, L.M., de Onis, M., \& Yip, R. (1997). The development of a MUACfor-height reference, including a comparison to other nutritional status screening indicators. Bulletin of the World Health Organization, 75(4), 333-341. Retrieved from https://www. ncbi.nlm.nih.gov/pmc/articles/PMC2486965/

NFHS-4 (2015-16). National Family Health Survey 2015-16, Ministry of Health and Family Welfare, New Delhi, Government of India

Moustakas, C. E. (1994). Phenomenological research methods. Thousand Oaks, Calif.: Sage. Nakkeeran N., Jadhav, S., Bhattacharya, A., Gamit, S., Mehta, C., Purohit, P., et al. (2020).

Recasting food: an ethnographic study on how caste and resource inequality perpetuates social disadvantage in India, CASTE: A Global Journal on Social Exclusion, 1(1), 1-16.

PIB-Ministry of Health and Family Welfare. (2016). India registers a significant decline in infant mortality rate (IMR). Retrieved from http://pib.nic.in/newsite/printrelease. aspx?relid=171251

PRS Legislative Research. (2017). Uttar Pradesh Budget Analysis 2017-18.

Sharma, A.K., Singh, S., Meena, S., \& Kannan, A.T. (2010). Impact of NGO-run Midday Meal program on nutrition status and growth of primary school children. Indian Journal of Pediatrics, 77(7), 763-769. DOI: 10.1007/s12098-010-0116-z

Singh, A., Park, A., \& Dercon, S. (2013). School meals as a safety net: an evaluation of the midday meal scheme in India. Economic Development and Cultural Change, 62(2), 275306. DOI: $10.1086 / 674097$

State Council for Educational Research and Training (SCERT). (2014). Study of Impact of Midday Meal (MDM) Programme on School Enrolment \& Retention. Retrieved from http://scert.cg.gov.in/pdf/researchpapers/studyreports/MDM\%20Chattisgarh\%20Final\%20 Report.pdf

Thorat, S. (2020) An Introduction to Caste (Introduction: Part 2), CASTE: A Global Journal on Social Exclusion, 1(1), p. ii-v.

Tiwari, R., \& Nayak, S. (2013). Drinking water and sanitation in Uttar Pradesh: a regional analysis. Journal of Rural Development, 32(1), 61-74.

World Bank Group (2016a). Uttar Pradesh, poverty, growth \& inequality. Retrieved from http:// documents.worldbank.org/curated/en/925341468185379316/pdf/105882-BRI-P157572ADD-SERIES-India-state-briefs-PUBLIC-UttarPradesh-AtAGlance.pdf

World Bank (2016b). Mortality rate, under-5 (per 1,000 live births) Data. Retrieved from https:// data.worldbank.org/indicator/SH.DYN.MORT?locations $=$ IN 


\section{Acknowledgment}

The authors would like to thank our international foundation donors who funded the research on which this paper is based. We would also like to thank all those who assisted and or contributed to the fieldwork phase of the study in Uttar Pradesh, India.

\section{Endnotes}

1 The physical features collected included weight, height, waist circumference, mid-upper arm circumference (MUAC), as well as an indication of unhealthy hair, unhealthy skin, stomach protrusion, and fainting experiences last week.

2 For instance, WHO suggests that children and adolescents experience stunting when their weight for age falls below the $3^{\text {rd }}$ percentiles of the reference population.

3 For students' satisfaction level, the factor analysis results in a single composite indicator. However, factor analysis on teachers' satisfaction level produces two composite indicators: the first factor with a strong representation of all aspects, except for menu variation; and the second factor with a strong representation of menu variation.

4 Including weight for age (WfA), height for age (HfA), body mass index (BMI) for age (BMIfA), waist circumference for age (WCfA), and waist circumference/height for age (WCHfA). The Indian Academy of Pediatrics growth tables of 2015 are used to define percentile cut-off for WfA, HfA, and BMIfA (Khadilkar et al., 2015). Results from a waistcircumference study in Urban South India in 2010 are used to determine percentile cut-off for WCfA and WCHfA (Kuriyan et al.,2010).

5 A USA-based study is used to define a standard deviation cut-off for MUAC for height (Mei et al., 1997). 